\title{
Analisa Plat Lantai Dasar Gedung Serbaguna Politeknik Negeri Balikpapan
}

\author{
Mahfud \\ Teknik Sipil, Politeknik Negeri Balikpapan \\ e-mail : mahfud@poltekba.ac.id
}

\begin{abstract}
Many way of to be able to know density of land ground. One of the way that test of sand cone as according to conducted by examination at project o public building politectic state of Balikpapan. This test is conducted to get dry land volume to weight original land;ground and also land;ground result of work of condensation, and also to know difference plate restating dance grade on slab and suspended. Heavy value obtained dry land volume through attempt of this cone sand, is used to evaluate result of work condensation of expressed field in Degree of Condensation (Degree Of Compaction) in set of \% with minimum value 95 is $\%$. Thick used by plate is $12 \mathrm{~cm}$ as according to calculation writer and also from field. Bone distance grade on slab land;ground is D 10-100 for the direction of X and D 10-150 for the direction of $Y$, while suspended land; ground used D 10-150 for the direction of $X$ and $Y$.
\end{abstract}

Keyword : Tes Sand cone, slab on great, suspended

\begin{abstract}
Abstrak
Banyak cara untuk dapat mengetahui kepadatan tanah. Salah satu cara adalah dengan test sand cone sesuai dengan pengujian yang dilakukan pada pembangunan gedung sebaguna Politeknik Negeri Balikpapan. Test ini dilakukan untuk mendapatkan berat volume tanah kering pada tanah asli maupun pada tanah hasil suatu pekerjaan pemadatan, serta untuk mengetahui perbedaan penulangan plat lantai slab on grade dan suspended. Nilai berat volume tanah kering yang diperoleh melalui percobaan sand cone ini, digunakan untuk mengevaluasi hasil pekerjaan pemadatan dilapangan yang dinyatakan dalam Derajat bPemadatan (Degree of Compaction) dalam satuan \% dengan nilai minimum $95 \%$. Tebal plat yang digunakan adalah $12 \mathrm{~cm}$ sesuai dengan perhitungan penulis maupun dari lapangan. Jarak tulangan pada tanah slab on grade adalah D 10-100 untuk arah X dan D 10-150 untuk arah Y, sedangkan pada tanah suspended digunakan D 10-150 untuk arah X dan $Y$.
\end{abstract}

Kata kunci : Tes sand cone, slab on great, suspended

\section{Pendahuluan}

Plat-plat lantai beton yang dicor langsung diatas tanah bukanlah hal yang mudah, dalam hal ini sering terjadi kegagalan akibat penurunan yang tidak sama besarnya atau pembebanan yang melampaui beban batas yang menyebabkan terjadinya keretakan serta terjadinya penyusutan akibat perubahan volume. Dalam hal ini, secara konservatif dilakukan perkerasan yang agak tinggi mengenai beban kerja yang sebenarnya terjadi, dan tebal dari plat beton dipilih sedemikian rupa sehingga tegangan geser yang terjadi akibat pembebanan yang ditentukan masih berada dibawah kekuatan tarik beton dengan jumlah selisih yang memadai. Bahkan kegagalan tersebut mungkin dapat terjadi tanpa 
diketahui untuk jangka waktu yang cukup lama. Namun demikian, dengan terjadinya kegagalan fungsi dari struktur sering kali sangat merugikan, dan perbaikanperbaikannya bukan saja sukar untuk dilakukan tetapi juga memerlukan biaya yang sangat besar. Plat-plat yang ditunjang oleh tanah direncanakan atas dasar perhitungan elastis dengan memperhatikan kepadatan tanah yang ada dilapangan atau dilokasi proyek. Pada kebanyakan kasus, dipakai sejumlah minimum tulangan untuk mendistribusikan dan mengendalikan lebar retak beton yang terjadi akibat adanya perubahan temperatur dan penyusutan. Metode untuk menganalisis plat yang ditumpu oleh tanah dan dibebani dengan beban terpusat adalah serupa denagn metode yang telah dikembangkan untuk tie beam yang terletak diatas pondasi yang elastis. Pada proyek tersebut perhitungan yang pertama dilakukan ialah menentukan kepadatan tanah dengan menggunakan tes sand cone dengan syarat kepadatan minimum dilapangan tidak kurang dari $95 \%$, dan menentukan perhitungan statikanya agar didapatkan momen, gaya lintang, gaya normal dengan menggunakan metode struktur aplikasi yang berguna untuk perhitungan selanjutnya yaitu menentukan besar diameter tulangan, tebal plat, jumlah lapis tulangan, dan jumlah tulangan pada plat lantai.

Didalam struktur gedung beton bertulang pada bagian plat lantai khususnya lantai dasar terdapat dua istilah dalam pemakaian penulangan ditinjau dari kepadatan tanahnya, yaitu suspended yang digunakan pada lapisan tanah urug dengan menggunakan struktur penulangan dua lapis dengan ketebalan mengikuti perhitungan struktur, sedangkan slab on gread merupakan struktur penulangan plat lantai satu lapis pada tanah asli. Dari sini kita bisa mengetahui segi efisiensi yang ada di lapangan dengan meninjau struktur tanah dan jumlah penulangan yang di pakai.

\section{Bahan Dan Metode}

Pembangunan gedung serbaguna Politeknik Negeri Balikpapan yang dimulai dari bulan agustus dan berakhir bulan desember 2014. Peneliti hanya membahas pada perhitungan tebal plat lantai, jarak tulangan yang digunakan, besar diameter tulangan yang digunakan, pengaruh tanah terhadap jumlah lapis tulangan, serta hasil kapadatan tanah dengan test sand cone. Adapun alat dan bahan yang digunakan dalam pengujian Sand Cone antara lain :

a. Peralatan

Tabung kalibrasi pasir uji, Botol tempat pasir uji, Kerucut yang dilengkapi dengan kran, Plat dasar yang berlubang

b. Sekop kecil, linggis, palu, alat perata

c. Timbangan dengan ketelitian 1 gram

d. Pasir uji berupa pasir Ottawa atau dapat pula pasir Kwarsa

e. Kantung plastik

f. Air suling untuk kalibrasi

g. Cawan dari bahan yang tidak mudah berkarat

h. Oven listrik dengan temperatur yang dapat diatur

i. Alat tulis

Pekerjaan kalibrasi dilakukan dilaboratorium Dinas PU Propinsi Kalimantan Timur yang terdiri atas :

1. Kalibrasi berat Volume pasir uji

a. Timbangan silinder kalibrasi pasir uji (W1).

b. Isi silinder kalibrasi tersebut dengan pasir uji sampai penuh.

c. Ratakan pasir pada permukaan silinder, lalu timbang silinder kalibrasi tersebut (W2).

d. Ganti pasir uji pada silinder kalibrasi dengan air yang diisi sampai penuh, kemudian timbang beratnya (W3).

e. Hitung berat volume pasir uji dengan menggunakan rumus:

$\gamma$ sand $=\frac{W 2-W 1}{W 3-W 1}$ 
2. Kalibrasi berat pasir uji dalam kerucut

a. Isi botol uji dengan pasir sebanyak 2/3 bagian, lalu timbang beratnya (W4).

b. Letakkan plat dasar pada lantai yang datar, kemudian letakkan botol uji ditengah plat tersebut dan buka kran kerucut, Biarkan pasir mengisi kerucut hingga penuh.

c. Setelah pasir penuh mengisi kerucut, tutup kran, angkat botol uji, kemudian timbang botol berikut pasir yang masih tersisa (W5).

d. Hitung berat pasir yang berada dalam kerucut dengan menggunakan rumus:

$$
\mathrm{W} 6=\mathrm{W} 4-\mathrm{W} 5
$$

Sedangkan prosedur pengujian test sand cone adalah sebagai berikut:

1. Bersihkan lokasi yang akan diuji kepadatannya selebar plat dasar Sand Cone

2. Ratakan permukaan tanahnya, letakkan plat dasar diatasnya

3. Buat lubang dengan diameter sebesar lubang pada plat dasar dengan kedalaman kurang lebih sama dengan diameternya.

4. Tanah hasil galian dikumpulkan seluruhnya dan dimasukkan ke dalam kantung plastik, kemudian timbang beratnya (W7). Ambil sebagian tanah tersebut untuk diukur adar airnya

5. Siapkan botol uji yang telah berisi pasir, timbang beratnya (W8).

6. Letakkan botol uji dengan kerucut dibawahnya tepat di atas plat dasar. Buka kran kerucut agar pasir uji yang berada dalam botol mengisi lubang pada tanah yang sudah digali.

7. Setelah lubang dan kerucut penuh terisi pasir, tutup kran kerucut, timbang botol berikut pasir yang tersisa didalamnya (W9).

8. Ambil kembalikan pasir uji yang berada dalam lubang tanah.
Adapun langkah-langkah pengujian tes sand cone adalah sebagai berikut:

1. Data yang didapatkan dari proses kalibrasi, yaitu:

a. Berat volume pasir uji, yaitu:

$$
\gamma \text { sand }=\frac{W 2-W 1}{W 3-W 1}
$$

b. Berat pasir uji dalam kerucut, yaitu:

$$
\mathrm{W} 6=\mathrm{W} 4-\mathrm{W} 5
$$

2. Data yang didapat dari lapangan, yaitu:

a. Berat tanah hasil galian (W7).

b. Berat botol, kerucut dan pasir uji sebelum pengujian (W8).

c. Berat botol, kerucut dan pasir uji setelah pengujian (W9).

d. Kadar air tanah hasil galian (didapat melalui proses laboratorium).

3. Data yang didapat dari hasil analasa, yaitu:

a. Berat pasir uji dalam lubang dan kerucut

$\mathrm{W} 10=\mathrm{W} 8-\mathrm{W} 9$

b. Berat pasir uji dalam lubang $\mathrm{W} 11=\mathrm{W} 10-\mathrm{W} 6$

c. Volume lubang galian

$$
\mathrm{Vh}=\frac{W 11}{\gamma \text { sand }}
$$

d. Berat volume tanah basah

$$
\gamma=\frac{W 7}{V h}
$$

e. Berat volume tanah kering

$$
\gamma d=\frac{\gamma}{1+W}
$$

Pada plat slab on grade digunakan pada tanah asli dengan menggunakan jumlah tulangan satu lapis sedangkan untuk suspended digunakan pada tanah urug dengan jumlah tulangan dua lapis. Plat lantai adalah elemen horizontal utama yang menyalurkan beban hidup ke rangka pendukung vertikal dari suatu sistem 
struktur. Elemen tersebut dapat berupa plat diatas balok, atau waffel slab, flat slab (slab tanpa balok yang bertumpu langsung pada kolom), atau slab komposit diatas joint. Elemen-elemen tersebut dapat dibuat sehingga bekerja dalam satu arah (slab satu arah) atau bekerja dalam dua arah yang saling tegak lurus (slab dua arah dan flat plate). Jarak antara batang-batang tulangan tidak boleh lebih besar dari $20 \mathrm{~cm}$ atau 2 kali tebal plat. Apabila tulangan plat dikurangi karena momennya berkurang, maka jaraknya tidak boleh lebih dari 40 $\mathrm{cm}$. Jarak tulangan pokok ke tulangan pokok antara tulangan pembagi yang dipasang tegak lurus pada tulangan pokok, tidak boleh lebih dari $25 \mathrm{~cm}$.

\section{Pembebanan}

Beban-beban yang bekerja pada struktur plat lantai dapat dibagi dalam tiga kategori utama:

1. Beban Mati adalah beban yang besar dan letaknya adalah tetap selama masa kerja struktur. Biasanya sebagian besar beban mati terdiri dari berat sendiri struktur. Pada umumnya beban mati dapat dihitung dengan ketetapan yang baik dari konfigurasi perencanaan dan dimensi struktur.

2. Beban hidup dari suatu bangunan terutama terdiri dari beban manusia yang mengisinya serta beban yang bergerak diatasnya. Beban-beban ini bisa bekerja secara penuh atau sebagian atau sama sekali tidak ada dan lokasi bekerjanya juga bisa berubah-ubah. Pada suatu saat tertentu, besar dan distribusi beban ini tidaklah tetap, dan bahkan intensitas maksimumnya sepanjang masa kerja struktur tidak dapat diketahui dengan tepat. Spesifikasi dari beban hidup uuntuk bangunan sering dikenal sebagai standar ANSI 1-1972. Spesifikasi tersebut memberikan distribusi beban hidup terbagi rata untuk berbagai jenis cara penempatan pada bangunan, yang juga mencakup ketentuan-ketentuan mengenai kejut bila diperlukan.

3. Beban alam terutama terdiri dari baban salju, tekan dan tarik angin, beban gempa bumi (yaitu, gaya-gaya inersia yang disebabkan oleh gerakan gempa bumi), tekanan tanah pada bagian struktur yang berada didalam tanah, beban-beban akibat adanya kolam air atau air hujan pada atap yang rata, dan gaya-gaya yang timbul karena adanya perbedaan temperatur. Banyak informasi mengenai sebagian besar beban-beban alam, yang sering kali dimodifikasi berdasarkan keadaan setempat, misalkan saja,tergantung pada, iklim setempat atau kondisikondisi mengenai gempa yang pernah terjadi disuatu tempat.

Karena besar beban maksimum yang akan terjadi selama masa kerja suatu struktur tidak dapat ditentukan, maka besarnya besarnya bebam maksimum dapat dianggap sebagai suatu variabel yang sembarang. Walaupun besar beban ini tidak tertentu, seorang rekayasa sipil harus dapat membuat suatu struktur yang cukup kuat untuk memikul beban tersebut.

Perencanaan untuk beban-beban terpusat dan metode untuk menganalisis plat lantai yang ditumpu oleh tanah dan dibebani dengan beban-beban terpusat adalah serupa dengan metode yang telah dikembangkan untuk tie beam yang terletak diatas pondasi yang elastis.

Apabila sebuah plat lantai yang ditumpu pada keempat sisinya dibebani dengan beban terbagi merata, maka akan terjadi kecenderungan bahwa sudut-sudut plat tersebut akan naik keatas. Dalam kasuskasus praktis hal ini tidak dapat terjadi, karena plat lantai tersebut dicor secara monolit dengan tie beam pendukungnya. Akibatnya terdapat momen pada sudut plat yang menyebabkan terjadinya gaya tarik pada bagian atas plat dalam arah diagonal panel tersebut. Demikian juga halnya, walaupun telah dikemukakan berbagai 
asumsi dalam analisis, sebuah plat lantai cenderung mempunyai bentang dalam arah diagonal pada sudut-sudut yang terletak diantara tie beam penunjang. Hal ini menyebabkan timbulnya momen lentur, yang menghasilnya terjadinya tarik pada bagian bawah plat lantai dalam arah tegak lurus terhadap diagonal panel.

\section{Hasil Dan Pembahasan}

Data uji tes tanah pada type konstruksi: beton bertulang, untuk komponen konstruksi:

a. Komponen Plat

Tebal Plat Lantai

Slab on Gread: $12 \mathrm{~cm}$

Suspended : $12 \mathrm{~cm}$

b. Mutu Bahan

Mutu Beton untuk plat:

$\mathrm{Fc}=30 \mathrm{Mpa}$

Mutu Baja untuk Tulangan plat:

$\mathrm{Fy}=400 \mathrm{Mpa}$

c. Beban Hidup

Beban Hidup lantai : 400 kg/m2

d. diameter tulangan : D 10

\section{Kesimpulan}

hasil pengujian kepadatan tanah dengan test sand cone diperoleh nilai ratarata 96,149\% dengan kadar air rata-rata $12,578 \%$ dengan jarak sample tes dilakukan setiap jarak $30 \mathrm{~m} 2$, dan untuk tebal plat pada tanah slab on grade dihasilkan ketebalan $12 \mathrm{~cm}$ dengan jarak tulangan D 10-15 cm untuk arah X dan Y, sedangkan untuk tanah suspended didapat tebal plat $12 \mathrm{~cm}$ dengan jarak tulangan D 10-10 cm untuk arah Y dan jarak D 10-15 cm untuk arah $\mathrm{X}$.

\section{Saran}

Setiap perhitungan plat beton, harus memperhatikan benar-benar panel mana yang akan diambil dalam perhitungan agar dapat mewakili semua bagian perhitungan konstruksi serta faktor keamanan dan nilai reduksi yang mungkin terjadi terhadap struktur dengan berpedoman pada ketetapan yang telah ditentukan dengan mengacu pada standar perencanaan yang telah ditetapkan.

\section{Daftar pustaka}

R. F. Craing, (1987), Mekanika Tanah. Jakarta, erlangga.

Wolfgang Schueller (1989), Struktur Bangunan Bertingkat Tinggi. refika aditama, Bandung.

Dipohusodo Istimawan (1994), Struktur Beton Bertulang, gramedia Jakarta.

George Winter, Arthur. H. Nelson, (1993), Perencanaan Struktur Beton Bertulang, pradnya paramita, Jakarta.

Wiratman Wangsadinata, (1971), Peraturan Beton Bertulang Indonesia. Direktorat Penyelidikan Masalah Bangunan Direktorat Jendral Ciptakarya Departement Pekerjaan Umum dan Tenaga Listrik, Bandung. 